\title{
A PRODUÇÃO CIENTÍFICA SOBRE OS ACIDENTES DE TRABALHO COM MATERIAL PERFUROCORTANTE ENTRE TRABALHADORES DE ENFERMAGEM
}

Maria Helena Palucci Marziale ${ }^{1}$

Christiane Mariani Rodrigues ${ }^{2}$

Marziale MHP, Rodrigues CM. A produção científica sobre os acidentes de trabalho com material perfurocortante entre trabalhadores de enfermagem. Rev Latino-am Enfermagem 2002 julho-agosto; 10(4):571-7.

A investigação ora apresentada teve por objetivos identificar as abordagens metodológicas das pesquisas publicadas em periódicos indexados nas bases de dados Lilacs e Medline, nos últimos 16 anos, referentes, ao estudo dos acidentes de trabalho com material perfurocortante e a identificação dos fatores predisponentes à ocorrência de tais acidentes entre trabalhadores da enfermagem. Foram analisados 55 artigos, sendo 39 internacionais, e 16 nacionais. As abordagens metodológicas mais utilizadas foram descritiva de campo, pesquisa-ação e bibliográfica. Dentre os fatores predisponentes a ocorrência dos acidentes em vários países, destaca-se a prática inadequada de re-encape de agulhas e o inadequado descarte do material.

DESCRITORES: acidentes de trabalho, trabalhadores, enfermagem

\section{THE SCIENTIFIC PRODUCTION ON OCCUPATIONAL ACCIDENTS WITH NEEDLESTICK MATERIALS AMONG MEMBERS OF THE NURSING TEAM}

This study has the purpose to identify methodological approaches used in research articles published in the last 16 years by periodicals indexed to the Lilacs and Medline databases. Its authors searched for studies on occupational accidents involving needlestick materials in order to identify the facts that predispose this kind of accident among nursing workers. Fifty-five articles were analyzed, of which thirty-nine were international and sixteen were national. The most frequently used methodological approaches were field description, action research and bibliographic research. Among the factors that predispose this kind of accident in various countries, the inadequate practice of recapping needles and inadequate material disposal can be distinguished.

DESCRIPTORS: occupational accidents, nursing, workers

\section{LA PRODUCCIÓN CIENTÍFICA DE LOS ACCIDENTES DE TRABAJ O CON MATERIAL CORTO-PUNZANTE ENTRE TRABAJ ADORES DE ENFERMERÍA}

La investigación aquí presentada tuvo como objetivos identificar los abordajes metodológicos de las pesquisas publicadas en revistas indexadas en las bases de datos Lilacs y Medline en los últimos 16 años en relación con el estudio de los accidentes de trabajo con material corto-punzante y la identificación de los factores que predisponen la ocurrencia de tales accidentes entre trabajadores de enfermería. Fueron analizados 55 artículos siendo 39 internacionales y 16 nacionales. Los abordajes metodológicos más utilizados fueron descriptiva de campo, investigación-acción y bibliográfica. Dentro de los factores que predisponen la ocurrencia de los accidentes en varios países se destaca la práctica inadecuada de tapar las agujas y el inadecuado descarte del material.

DESCRIPTORES: accidentes de trabajo, trabajadores, enfermería

\footnotetext{
${ }^{1}$ Professor Livre-Docente, e-mail: marziale@eerp.usp.br; ${ }^{2}$ Enfermeira, Bolsista de Iniciação Científica - Projeto Integrado CNPq. Escola de Enfermagem de Ribeirão Preto, da Universidade de São Paulo, Centro Colaborador da OMS para o desenvolvimento da pesquisa em enfermagem
} 


\section{INTRODUÇÃO}

Os trabalhadores de enfermagem, durante a assistência ao paciente, estão expostos a inúmeros riscos ocupacionais causados por fatores químicos, físicos, mecânicos, biológicos, ergonômicos e psicossociais, que podem ocasionar doenças ocupacionais e acidentes de trabalho.

O contingente de trabalhadores de enfermagem, particularmente o que está inserido no contexto hospitalar, permanece 24 horas junto ao paciente, em sua grande maioria executa o "cuidar" dentro da perspectiva do "fazer" e, conseqüente, expõe-se a vários riscos, podendo adquirir doenças ocupacionais e do trabalho, além de lesões em decorrência dos acidentes de trabalho ${ }^{(1)}$.

Os riscos químicos referem-se ao manuseio de gases e vapores anestésicos, antissépticos e esterelizantes, drogas citostáticas, entre outros. A exposição aos riscos químicos está relacionada com a área de atuação do trabalhador, com o tipo de produto químico e tempo de contato, além da concentração do produto. Isso pode ocasionar sensibilização alérgica, aumento da atividade mutagênica e até esterilidade ${ }^{(2)}$.

Os riscos do ambiente de trabalho são classificados em real (de responsabilidade do empregador), suposto (quando se supõe que o trabalhador conhece as causas que o favorecem) e residual (de responsabilidade do trabalhador).

Os riscos físicos referem-se à temperatura ambiental (elevada nas áreas de esterelização e baixa em centro cirúrgico), radiação ionizante, ruídos e iluminação em níveis inadequados e exposição do trabalhador a incêndios e choques elétricos ${ }^{(3)}$.

Dentre os riscos psicossociais, está a sobrecarga advinda do contato com o sofrimento de pacientes, com a dor e a morte, o trabalho noturno, rodízios de turno, ritmo de trabalho, realização de tarefas múltiplas, fragmentadas e repetitivas, o que pode levar à depressão, insônia, suicídio, tabagismo, consumo de álcool e drogas e fadiga mental ${ }^{(4)}$.

Dentre os riscos mecânicos, estão as lesões causadas pela manipulação de objetos cortantes e penetrantes e as quedas ${ }^{(5)}$.

O freqüente levantamento de peso para movimentação e transporte de pacientes e equipamentos, a postura inadequada e flexões de coluna vertebral em atividades de organização e assistência podem causar problemas à saúde do trabalhador, tais como fraturas, lombalgias e varizes. Tais fatores causais estão relacionados a agentes ergonômicos ${ }^{(3,5)}$. Os fatores ergonômicos são aqueles que incidem na adaptação entre o trabalho-trabalhador. São eles o desenho dos equipamentos, do posto de trabalho, a maneira como a atividade laboral é executada, a comunicação e o meio ambiente.

Quanto aos riscos biológicos, eles se referem ao contato do trabalhador com microorganismos (principalmente vírus e bactérias) ou material infectocontagiante, os quais podem causar doenças como: tuberculose, hepatite, rubéola, herpes, escabiose e $\operatorname{AIDS}^{(2)}$.

O contato com microorganismos patológicos oriundo de acidentes ocasionados pela manipulação de material perfurocortante, ocorre, com grande freqüência, na execução do trabalho de enfermagem. A exposição ocupacional por material biológico é entendida ${ }^{(6)}$ como a possibilidade de contato com sangue e fluidos orgânicos no ambiente de trabalho, e as formas de exposição incluem inoculação percutânea, por intermédio de agulhas ou objetos cortantes, e o contato direto com pele e/ou mucosas.

O maior risco para os trabalhadores da área da saúde é o acidente com material perfurocortante, que expõe os profissionais a microorganismos patogênicos, sendo a hepatite $B$ a doença de maior incidência entre esses trabalhadores ${ }^{(7)}$.

Com o surgimento da AIDS, maior ênfase passou a ser dada à exposição desses trabalhadores ao sangue. A prevenção ocupacional do HIV tornou-se um grande desafio aos profissionais de Controle de Infecção Hospitalar e Saúde Ocupacional, depois de uma enfermeira ter desenvolvido AIDS, em conseqüência de picada acidental com uma agulha que continha sangue de um paciente infectado pelo HIV, internado em um hospital da Inglaterra ${ }^{(8)}$. O Centers for Disease ControlCDC, preocupado com a questão da transmissão de HIV e outros patógenos veiculados pelo sangue, organiza um sistema informatizado de coleta de informações (EPINet), a partir do qual propõe estratégias para minimizar o problema dos profissionais expostos ao risco ocupacional de contaminação( ${ }^{(9)}$.

Segundo dados do CDC, a estimativa anual de acidentes percutâneos com trabalhadores da saúde nos hospitais é de 384.325 casos, e o risco de contaminação 
com o vírus HIV (AIDS) é de $0,3 \%$, vírus HBV (Hepatite

B) é de $6 \%$ a $30 \%$, e o risco de contaminação é de $0,5 \%$ a $2 \%$ para o HCV (Hepatite C) $)^{(9)}$.

Segundo a referida instituição, as conseqüências da exposição ocupacional aos patógenos veiculados pelo sangue não são só os referentes às infecções, mas também os relativos ao trauma psicológico ocasionado pela espera do resultado de uma possível soroconversão e mudanças nas práticas sexuais, no relacionamento social e familiar, efeito das drogas profiláticas, entre outros.

Em estudo realizado no Brasil, com trabalhadores da saúde, visando à identificação do risco ocupacional de infecção pelo vírus da imunodeficiência humana ${ }^{(10)}$, foi constatado que $88,8 \%$ dos acidentes de trabalho notificados acometeram o pessoal da enfermagem.

Dentre os fatores predisponentes a ocorrência de acidentes de trabalho dessa natureza, está a freqüente manipulação de agulhas pelos trabalhadores de enfermagem ${ }^{(11)}$.

A Secretaria da Saúde do Estado de São Paulo, por meio do programa de DST/AIDS ${ }^{(12)}$ recomenda que os acidentes que envolvam exposição à material biológico sejam analisados quanto ao material biológico envolvido, ao tipo de acidente e à situação sorológica do paciente fonte em relação ao HIV. Se for indicado quimioprofilaxia, ela deverá ser iniciada nas primeiras 2 horas após o acidente, tendo duração de 4 semanas ou até que se tenha o resultado da sorologia do paciente fonte.

Embora considerável progresso tenha sido observado sobre o entendimento do risco ocupacional e $\mathrm{HIV}^{(13)}$, os trabalhadores da saúde e, principalmente, os da enfermagem têm se mostrado resistentes à utilização de equipamentos de proteção individual, à subestimação do risco de se infectar e à notificação do acidente de trabalho.

O acidente de trabalho em nosso país deve ser comunicado imediatamente após sua ocorrência, por meio da emissão da Comunicação de Acidente de Trabalho (CAT), que deve ser encaminhada à Previdência Social, ao acidentado, ao sindicato da categoria correspondente, ao hospital, ao Sistema Único de Saúde (SUS) e ao Ministério do Trabalho ${ }^{(14)}$.

Apesar de, legalmente, ser obrigatória a emissão da CAT, observa-se, na prática, a subnotificação dos acidentes de trabalho. $O$ sistema de informação utilizado apresenta falhas devido à concepção fragmentada das relações de saúde e trabalho, marcada por uma divisão e alienação das tarefas dos profissionais responsáveis pelo registro da CAT, os quais privilegiam o cumprimento de normas burocráticas, mas não o envolvimento profissional com a questão acidentária ${ }^{(15)}$.

As causas da subnotificação de acidentes de trabalho ${ }^{(16)}$, na visão de trabalhadores de enfermagem de uma cidade do interior paulista, foram atribuídas à falta de importância dada às pequenas lesões, tal como picada de agulha, e o desconhecimento sobre a importância da emissão da CAT.

Diante da freqüente ocorrência de acidentes do trabalho ocasionados por material perfurocortante, observada em nossa atuação profissional, e por acreditarmos que o trabalhador de enfermagem deva se preocupar com a implementação de práticas que lhe ofereçam condições seguras para o desempenho de suas atividades laborais, propusemos-nos realizar a pesquisa ora apresentada cujos resultados contribuirão para divulgação do conhecimento produzido sobre a referida temática.

\section{OBJETIVOS}

- Identificar as abordagens metodológicas dos estudos que se relacionam com a questão dos acidentes do trabalho com material perfurocortante;

- Levantar os fatores predisponentes aos acidentes do trabalho, ocasionados por material perfurocortante, na equipe de enfermagem, descritos na literatura.

\section{MATERIAL E MÉTODO}

Foi realizado um levantamento bibliográfico retrospectivo, dos últimos 16 anos (2000-1985), por meio dos bancos de dados Lilacs (Literatura Latino Americana e do Caribe em Ciências da Saúde), Medline (National Library of Medicine), utilizando os unitermos "accidents occupational", "needlestick injuries", "nursing staff", "sharps", "percutaneous injuries", acidentes do trabalho, perfurocortante, trabalho de enfermagem, risco ocupacional, metodologia de pesquisa.

Os artigos foram catalogados e analisados buscando-se uma síntese dos fatores predisponentes aos acidentes do trabalho com material perfurocortante e as abordagens metodológicas utilizadas. 
Foi utilizado, para coleta de dados, um protocolo contendo informações sobre o periódico, tipo de metodologia usada (descritiva de campo, descritiva bibliográfica, pesquisa ação, exploratória, experimental, reflexão teórica e relato de experiência) e os fatores predisponentes à ocorrência dos acidentes. $\mathrm{O}$ referido instrumento foi submetido à apreciação de três enfermeiros pesquisadores, quanto à clareza, objetividade e conteúdo, sendo considerado adequado para o objeto estudado.

\section{RESULTADOS E DISCUSSÃO}

Foram analisados 55 artigos, sendo 39 internacionais e 16 nacionais. As pesquisas analisadas foram publicadas nos seguintes periódicos internacionais: "Pediatric Nursing", "Infection Control", "AAOHN Journal", "Arch Surgery", "American Journal of Preventive Medicine", "Rev. Investigação Clinica”, "AJIC", "American Journal of Public Health", "AORN Journal", "AIDS Care" e "The New England Journal of Medicine" e periódicos nacionais: Rev. Escola Enfermagem USP, Rev. Brasileira Enfermagem, Rev. Enfermagem UERJ, Rev. Brasileira de Saúde Ocupacional, Rev. Saúde Pública.

Através da Tabela 1, pode-se observar o número de publicações nacionais e internacionais, segundo o ano de publicação.

Tabela 1 - Publicações em periódicos nacionais e internacionais, no período de 1985 a 2000

\begin{tabular}{ccccc}
\hline Período de Publicação & \multicolumn{2}{c}{ Nacionais } & \multicolumn{2}{c}{ Internacionais } \\
& № & $\%$ & № & $\%$ \\
\hline$[1985-1988]$ & 04 & 25,00 & 07 & 17,90 \\
{$[1989-1992]$} & 05 & 31,20 & 11 & 28,20 \\
{$[1993-1996]$} & 02 & 12,50 & 09 & 23,10 \\
{$[1997-2000]$} & 05 & 31,30 & 12 & 30,80 \\
Total & 16 & 100 & 39 & 100 \\
\hline
\end{tabular}

O aumento no número de publicações, no início da década de 90 , pode estar relacionado às descobertas da transmissão dos vírus HIV e HBV, no contato com sangue, via acidente perfurocortante.

Em três dos artigos (5,50\%), foi utilizada a análise qualitativa dos dados, cujo objetivo era compreender as causas dos acidentes perfurocortantes. Nos outros 52 $(94,50 \%)$, foi utilizada a análise quantitativa para tratamento dos dados.
Os dados relativos às abordagens metodológicas utilizadas nas pesquisas analisadas são apresentados na Tabela 2.

Tabela 2 - Distribuição de artigos nacionais e internacionais categorizados segundo a metodologia empregada pelos autores, 1985-2000

\begin{tabular}{lcc}
\hline \multicolumn{1}{c}{ Tipo de Pesquisa } & Número & $\%$ \\
\hline Descritiva de campo & 22 & 40,00 \\
Pesquisa-ação & 09 & 16,40 \\
Descritiva bibliográfica & 08 & 14,50 \\
Exploratória & 08 & 14,50 \\
Experimental & 05 & 9,10 \\
Reflexão teórica & 02 & 3,70 \\
Relato de experiência & 01 & 1,80 \\
Total & 55 & 100 \\
\hline
\end{tabular}

Foi observado que as metodologias mais freqüentemente empregadas nas pesquisas foram a descritiva de campo $(40,00 \%)$, descritiva bibliográfica $(14,50 \%)$, pesquisa-ação $(16,40 \%)$, exploratória $(14,50 \%)$.

A pesquisa descritiva baseia-se na descrição de fenômenos relativos à profissão, baseados em observação, descrição e classificação dos fenômenos observados. É uma modalidade de pesquisa muito utilizada na enfermagem. Ela se subdivide em pesquisa de campo, que busca a descrição dos fenômenos em cenários naturais, examinando profundamente as práticas, comportamentos e atitudes das pessoas ou grupos em ação na vida real; e pesquisa bibliográfica, que é uma modalidade da pesquisa descritiva, sendo feita leitura, seleção e registro de tópicos de interesse para pesquisa $^{(17)}$.

Pesquisa-ação é um tipo de pesquisa social, com base empírica, que é concebida e realizada em estreita associação com uma ação ou com a resolução de um problema coletivo, sendo que os pesquisadores e os participantes representativos da situação ou do problema estão envolvidos de modo cooperativo ou participativo ${ }^{(17)}$.

A pesquisa exploratória inicia-se por algum fenômeno de interesse e, além de observar e registrar a incidência do fenômeno, busca explorar as dimensões deste, a maneira pela qual ele se manifesta e os outros fatores com os quais ele se relaciona ${ }^{(17)}$.

$\mathrm{Na}$ pesquisa experimental, o pesquisador manipula a variável independente. Ele possui o controle sobre a variável independente, ou, conscientemente, manipula essa variável, observando, posteriormente, seu efeito sobre a variável dependente que lhe interessa ${ }^{(17)}$. 
Relato de experiência consiste em analisar e compreender variáveis importantes ao desenvolvimento do cuidado dispensado ao indivíduo ou a seus problemas, sendo o pesquisador um observador passivo ou ativo, e relatar, de forma clara e objetiva, suas observações ${ }^{(17)}$.

Em relação aos fatores predisponentes à ocorrência de acidente de trabalho com material perfurocortante, foi constatada por meio das pesquisas analisadas, que a categoria profissional mais acometida por esse tipo de infortúnio é a dos auxiliares de enfermagem, que são profissionais que estão em contato direto com o paciente, na maior parte do tempo, administrando medicamentos, realizando curativos e outros procedimentos que os mantêm em constante contato com material perfurante e cortante.

Pode-se abstrair, da análise dos resultados deste estudo, quanto à ocorrência de acidentes de trabalho e os dados apresentados em outros estudos ${ }^{(7,11,18-19)}$, que a ocorrência desse tipo de acidentes não está relacionada apenas ao nível de formação, mas também ao treinamento, capacitação, recursos materiais disponíveis e cultura local.

A análise dos artigos permitiu a identificação de que o principal fator associado a ocorrência do acidente percutâneo é o reencape de agulhas, o qual infringe as precauções-padrão, antigamente denominadas universais, e que os auxiliares e técnicos de enfermagem são os que mais comumente realizam esse procedimento inadequado.

As informações descritas nas pesquisas apontam que os enfermeiros atribuem, como causas dos acidentes, a sobrecarga de trabalho e negligência médica, e os atendentes de enfermagem os relacionam à fatalidade.

Em relação aos fatores predisponentes aos acidentes com material perfurocortante, por meio da Figura 1, são apresentados os fatores mais incidentes.

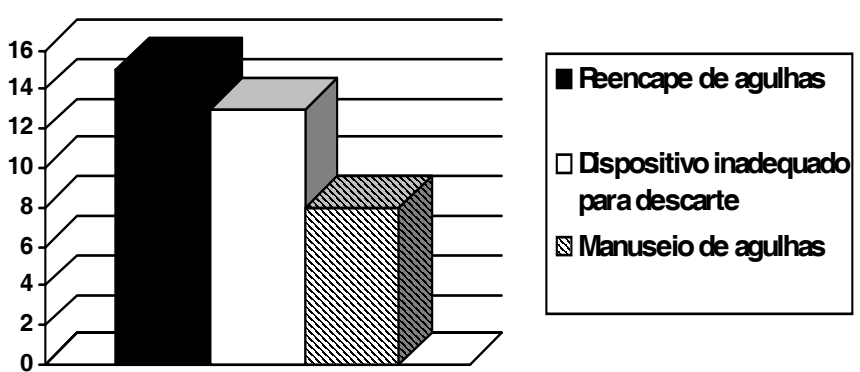

Figura 1 - Distribuição dos fatores apontados nos artigos analisados como principais fatores predisponentes à ocorrência de acidente perfurocortante, 1985-2000
A orientação para somente reencapar as agulhas usando-se um anteparo ou pinça, conforme consta das precauções padrão, não tem demonstrado ser eficaz na prevenção de acidentes, e o seu uso pode reduzir, mas não eliminar, o risco de exposição ocupacional ${ }^{(19)}$. A disponibilidade das caixas coletoras, utilizadas para descarte de material, pode ser considerada inadequada, na maioria dos casos. Recomenda-se que deve haver caixas para descarte disponíveis para pronta substituição e que deve ser evitado o seu enchimento excessivo, sendo que a tarefa de substituição deve ser realizada por funcionários treinados dos serviços gerais, e não pelo pessoal da enfermagem.

Os fatores predisponentes à ocorrência de acidentes com material perfurocortante identificados por meio das pesquisas estão apresentados na Tabela 3.

Tabela 3 - Fatores predisponentes à ocorrência de acidentes de trabalho com material perfurocortante descritos na literatura, 1985-2000

Fatores relacionados às condições em que o trabalho é executado

${ }^{*}$ Comportamento agressivo de pacientes

*Situações de urgência

*Funcionários temporários

${ }^{*}$ Falta de programas de capacitação do pessoal

*Disposição inadequada das caixas de descarte na unidade (distante da área de manipulação de perfurocortantes)

${ }^{*}$ Recipiente de descarte superlotado

*Sobrecarga de trabalho, devido a falta de funcionários

${ }^{*}$ Falta de recipiente adequado para descarte de material pérfurocortante

*Não oferta de materiais e equipamentos de segurança

Fatores relacionados ao comportamento individual dos trabalhadores

*Desconsideração das precauções padrão

*Desconhecimento dos riscos de infecção

*Desatenção e descuido dos profissionais

*Tensão e estresse dos profissionais

*Falta de capacitação profissional (técnico)

${ }^{*}$ Cansaço, fadiga

*Fatalidade

*Manipulação de material perfurocortante

*Transporte do material perfurocortante

*Desconexão de agulhas das seringas

*Re-encape de agulhas

${ }^{*}$ Quebra de ampola sem dispositivo de proteção

*Má qualidade de materiais

Fonte bibliográfica: 1-2,6-7,11-13,19-22

Por meio dos dados descritos na Tabela 3 podese perceber que uma série de fatores podem estar associados à ocorrência de acidentes de trabalho, dentre os quais existe relação com a peculiaridade das atividades laborais da enfermagem, da manipulação de 
materiais de design que não oferecem segurança, da forma de organização do trabalho, do comportamento dos próprios profissionais e das condições de trabalho oferecidas.

Os dados da literatura analisada indicam que a falta de sensibilização e conscientização, a inadequada supervisão contínua e sistemática da prática, a não percepção individual sobre o risco e a falta de educação continuada são fatores associados à ocorrência de acidentes de trabalho com material perfurocortante.

\section{CONCLUSÕES}

Os resultados obtidos através desta pesquisa permitem as seguintes conclusões:

Durante o período de 1985 a 2000, foram encontrados 55 artigos indexados cuja temática abordava a questão dos acidentes de trabalho com material perfurocortante. Na grande maioria das pesquisas, foi utilizada a análise quantitativa dos dados, e as abordagens metodológicas para estudar o objeto foram variadas, havendo predominância do tipo de pesquisa descritiva (54,50\%). Alguns autores (16,40\%) utilizaram a pesquisa-ação, $(14,50 \%)$ a pesquisa exploratória, $(9,10 \%)$ pesquisa experimental, $(1,80 \%)$ o relato de experiência e $(1,80 \%)$ a reflexão teórica.

Em relação aos fatores predisponentes, podese concluir que o reencape de agulhas, a inadequação dos dispositivos utilizados para descarte e o manuseio de agulhas foram os principais fatores identificados nas pesquisas analisadas. Uma série de outros fatores, no entanto, são atribuídos pelos autores como predisponentes à ocorrência de acidentes de trabalho dessa natureza tais como: situações de urgência, a falta de capacitação dos profissionais, sobrecarga de trabalho, fadiga, transporte de material perfurocortante, má qualidade dos materiais, desconhecimento dos profissionais sobre os riscos de infecção e desconsideração das precauções padrão recomendadas, desatenção.

\section{CONSIDERAÇÕES FINAIS}

Verificou-se que o interesse em relação aos acidentes do trabalho com material perfurocortante vem aumentando, principalmente após a década de 90, devido aos danos causados à saúde dos trabalhadores e às instituições e o aumento no número de casos de AIDS.

Sabe-se que os maiores riscos dos acidentes perfurocortantes não são as lesões, mas os agentes biológicos veiculados pelo sangue e secreções corporais, principalmente o HIV e HBV, que estão presentes nos objetos causadores.

No Brasil, a escassez de dados sistematizados sobre esses acidentes não nos permite conhecer a magnitude global do problema, dificultando, assim, a avaliação das medidas preventivas utilizadas atualmente.

A análise dos resultados sugere que todas as categorias de profissionais de enfermagem estão sujeitas a acidentes com material perfurocortante, o que faz necessária a realização de estudos aprofundados que detectem as causas mais comuns e as conseqüências para os profissionais, para possibilitar a elaboração de programas de educação, treinamento dos profissionais, supervisão contínua e sistemática e modificações nas rotinas de trabalho, tornando um hábito a prática das precauções de segurança.

Além da utilização das precauções padrão como medida preventiva, encontram-se disponíveis, no mercado, dispositivos considerados seguros, como os sistemas sem agulhas, os de agulhas retráteis e os sistemas protetores de agulhas.

Apesar de a literatura americana demonstrar o impacto positivo desses dispositivos na redução do número de acidentes perfurocortantes, a maioria das instituições de saúde no Brasil não tem perspectivas de implantá-los a curto prazo, devido a seu elevado custo.

É importante que se elabore e implemente um programa de educação continuada que aborde a questão dos acidentes e exposição a material biológico, esclarecendo os trabalhadores de enfermagem sobre a importância da notificação, busca de atendimento médico nas 2 horas que seguem o acidente, sensibilizá-los sobre a eficácia da vacina para prevenção da hepatite $B$, esclarecer sobre a utilização de EPI e precauções padrão.

O sucesso de qualquer programa educativo está diretamente ligado à participação e reconhecimento por parte dos trabalhadores e apoio da instituição. 


\section{REFERÊNCIAS BIBLIOGRÁFICAS}

1. Bulhões I. Riscos do trabalho de Enfermagem. Rio de Janeiro: Folha Carioca; 1998.

2. Jansen AC. Um novo olhar para os acidentes de trabalho na enfermagem: a questão do ensino. [dissertação]. Ribeirão Preto (SP): Escola de Enfermagem de Ribeirão Preto/USP; 1997.

3. Marziale MHP, Carvalho EC. Condições ergonômicas do trabalho da equipe de enfermagem em unidade de internação de cardiologia. Rev Latino-am Enfermagem 1998 jan; 6(1):99117.

4. Estryn-Behar M. Ergonomia hospitalar: teoria e prática. $7^{\circ}$ Encontro Nacional de Enfermagem do Trabalho,1996 agosto; Rio de Janeiro, Brasil, 1996. p. 96-105.

5. SilvaVEF. Estudo sobre acidentes de trabalho ocorridos com trabalhadores de Enfermagem de um hospital de ensino. [dissertação]. Ribeirão Preto (SP): Escola de Enfermagem de Ribeirão Preto/USP; 1988.

6. Brevidelli MM. Exposição ocupacional aos vírus da AIDS e da hepatite B: análise da influência das crenças em saúde sobre a prática de re-encapar agulhas. [dissertação]. São Paulo (SP): Escola de Enfermagem/USP; 1997.

7. Figueiredo RM. Opinião dos servidores de um hospital escola a respeito de acidentes com material perfurocortante na cidade de Campinas-SP. Rev Bras Saúde Ocupacional 1992 jul/dez; 20(76):26-33.

8. Needlesticks transmission of HTLV-III from a patient infected in África. Editorial. Lancet 1984; 2(8416):1376-7.

9. International Health Care Worker - Safety Center. Risk of infection: following a single HIV, HBV, or HCV - contaminated needlestick or sharp instrument injury. University of Virginia, Virginia-EUA [serial online] 1999. Available from: URL: http:// www.medvirginia.edu

10. Machado AA. Risco de infecção pelo vírus da imunodeficiência humana (HIV) em profissionais da saúde. Rev Saúde Pública 1992; 26(1):54-6.

11. Murphy $D$. The development of risk management program in response to the spread of bloodborne pathogen illnesses. J Intrav Nurs1995; 8(65):543-7.

12. Secretaria do Estado da Saúde (SP). Programa DST/AIDS, Brasil. 1999 dezembro. 141(99).

13. Marcus R, Bell DB. Occupational risk of human immunodediciency virus-infection in health care workers. In: de Vita VT. AIDS: etiology, diagnosis, treatment and prevention. $4^{\mathrm{a}}$ ed. Philadelphia (EUA): Lippincott-Raven; 1997.

14. Marcelino IV. O sistema de informações sobre acidentes do trabalho no município de Ribeirão Preto, São Paulo, Brasil, no ano de 1998: uma abordagem qualitativa. [dissertação]. Ribeirão Preto (SP): Faculdade de Medicina de Ribeirão Preto/ USP; 1999.

15. Barros AJP, Lehfeld NAS. Fundamentos de metodologia: um guia para iniciação científica. São Paulo (SP): Mc GrawHill; 1986.

16. Canini SRMS, Gir E, Hayashida M, Machado AA. Acidentes perfurocortantes entre trabalhadores de enfermagem de um hospital universitário do interior paulista. Rev Latino-am Enfermagem 2002 mar/abr; 10(2):172-8.

17. Polit DF, Hungler BP. Fundamentos de pesquisa em enfermagem. 2 $2^{\text {a }}$ ed. Porto Alegre (Brasil): Artes Médicas; 1995. 18. Souza M; Vianna, LAC. Incidência de acidentes de trabalho relacionada com a não utilização das precauções universais. Rev Bras Enfermagem 1993 jul/dez; 46(3/4):234-44.

19. Lopes MHB de M, Moromizato SS, Silva JFF. Adesão as medidas de precaução padrão: relato de experiência. Rev Latino-am Enfermagem 1999 out; 7(4):83-8.

20. Monteiro MS, Carnio AM, Alexandre NMC. Acidentes de trabalho entre o pessoal de enfermagem de um hospital universitário. Rev Bras Enfermagem 1987 abr/set; 40(2/3):8992.

21. Kopfer AM, Mc Govern PM. Transmission of HIV via a needlestick injury. AAOHN J 1993 aug; 41(8):374-81.

22. Hanharan A, Reutter LA. Critical review of the literature on shayes injuries. J Adv Nurs 1997; 25:144-54. 